\title{
VISÃO DOS DOCENTES DE ENFERMAGEM SOBRE A FORMAÇÃO DE ENFERMEIROS-LÍDERES*
}

\author{
Veridiana Corrêa Ávila1, Simone Coelho Amestoy², Adrize Rutz Porto³, Maira Buss Thofehrn ${ }^{4}$, \\ Letícia de Lima Trindade ${ }^{5}$ Aline Belletti Figueira ${ }^{1}$
}

\begin{abstract}
RESUMO: Objetivou-se conhecer a visão dos docentes de uma faculdade de Enfermagem sobre a formação de enfermeiroslíderes. Trata-se de uma pesquisa de abordagem qualitativa do tipo descritiva e exploratória, na qual participaram 9 docentes de uma universidade pública federal. As informações foram obtidas no mês de abril de 2012 por meio de entrevistas semiestruturadas, e analisados por meio da Análise Temática da qual emergiram dois temas: Visão dos docentes sobre liderança e Estratégias que auxiliam na formação de enfermeiros-líderes. Os docentes e a literatura enfatizam a relevância da abordagem do tema liderança nas disciplinas, de forma transversal e desde os semestres iniciais da formação acadêmica, e sinalizam estratégias para que isso ocorra.
\end{abstract}

PALAVRAS-CHAVE: Enfermagem; Liderança; Educação em enfermagem; Docentes.

\section{THE VIEW OF NURSING STUDENTS ON THE TRAINING OF NURSE-LEADERS}

ABSTRACT: The aim was to investigate the view of professor's team about the training of nurse-leaders. This research has a qualitative approach and is descriptive and exploratory: 9 students participated, from a public federal university. The information was obtained in April 2012 through semi-structured interviews, and analyzed by thematic analysis, from which two themes emerged: View of students on leadership and Strategies which help in the training of nurse-leaders. The students and the literature emphasize the relevancy of addressing the theme of leadership in the courses, in a crosssectional way and from the first semesters of academic training, and indicate strategies such that this may occur.

KEYWORDS: Nursing; Leadership; Nursing education; Students.

\section{VISIÓN DE LOS DOCENTES DE ENFERMERÍA SOBRE LA FORMACIÓN DE ENFERMEROS-LÍDERES}

RESUMEN: La finalidad del estudio fue conocer la visión de los docentes de una facultad de enfermería acerca de la formación de enfermeros-líderes. Es una investigación de abordaje cualitativo del tipo descriptivo y exploratorio, en la cual participaron 9 docentes de una universidad pública federal. Las informaciones fueron obtenidas en el mes de abril de 2012 por medio de entrevistas semiestructuradas, y analizadas por medio del Análisis Temático, resultando en dos temas: Visión de los docentes sobre liderazgo y Estrategias que ayudan en la formación de enfermeros-líderes. Los docentes y la literatura enfatizan la relevancia del abordaje del tema liderazgo en las asignaturas, de forma transversal y desde los semestres iniciales de la formación académica, y apuntan estrategias para que eso ocurra.

PALABRAS CLAVE: Enfermería; Liderazgo; Educación en enfermería; Docentes.

\footnotetext{
* Artigo desenvolvido a partir de Monografia de Graduação em Enfermagem intitulada: Visão dos docentes de enfermagem sobre a formação de enfermeiros-líderes, apresentada à Universidade Federal de Pelotas-UFPel, em 2012.

${ }^{1}$ Enfermeira.

${ }^{2}$ Enfermeira. Doutora em Enfermagem. Professora do Departamento e do Programa de Pós-Graduação da Faculdade de Enfermagem da UFPel. Membro do Grupo de Pesquisa em Educação em Enfermagem e Saúde - EDEN e do Núcleo de Estudos e Pesquisas em Enfermagem - NEPEN.

${ }^{3}$ Enfermeira. Doutoranda em Enfermagem pelo Programa de Pós-Graduação da Universidade Federal do Rio Grande do Sul - UFRGS. ${ }^{4}$ Enfermeira. Doutora em Enfermagem. Professora do Departamento e do Programa de Pós-Graduação da Faculdade de Enfermagem da UFPel. Membro do NEPEN.

${ }^{5}$ Enfermeira. Doutora em Enfermagem. Professora da Universidade do Estado de Santa Catarina - UDESC. Membro do Grupo Práxis UFSC e Líder do Grupo de Pesquisa sobre Saúde e Trabalho - GESTRA UDESC.
}

Autor correspondente:

Recebido: $23 / 08 / 2012$

Simone Coelho Amestoy Aprovado: 30/11/2012

Universidade Federal de Pelotas

Rua Gomes Carneiro, 01 - 96010-610 - Pelotas-RS-Brasil

E-mail: simoneamestoy@hotmail.com 


\section{INTRODUÇÃO}

O enfermeiro traz em sua essência o contato com o outro no exercício da arte de cuidar, como também gerindo equipes e preocupando-se com quem cuida. Além disso, esse profissional busca solucionar conflitos, pratica o bom senso e a justiça na tomada de decisões, norteia-se pela ética e lei do exercício profissional, orienta novas ações, estimula a participação dos integrantes da equipe na construção de planos e projetos, com o intuito de alcançar objetivos ${ }^{(1)}$.

No entanto, para a formação do profissional enfermeiro com essas qualidades, o ensino da Enfermagem passou, e vem passando, por várias modificações ao longo dos anos, resultantes de mudanças nos diversos contextos históricos e de reflexões acerca da práxis de Enfermagem. Em decorrência disso, o perfil dos enfermeiros igualmente apresentou significativas transformações ${ }^{(2)}$. Este aspecto exigiu desses trabalhadores a adaptação em seu desenvolvimento para acompanhar as exigências e evolução de cada época ${ }^{(3)}$.

Da mesma forma, as modificações em nossa sociedade e nas políticas de saúde são fatores determinantes para a construção do processo de ensino-aprendizagem da enfermagem e formação de profissionais engajados em intervir na realidade de saúde. Nesse sentido, compreende-se a educação como possibilidade de transformação, centrada no desenvolvimento da consciência crítica, levando o enfermeiro à reflexão sobre a prática profissional e o compromisso com a sociedade ${ }^{(2)}$.

Diante disso, em 2001, foram instituídas as novas Diretrizes Curriculares do Curso de Graduação em Enfermagem baseadas em competências. Tais diretrizes definem a formação de enfermeiros generalistas e humanos, capazes de aprender a aprender, criticar e refletir sobre a realidade e de atender as necessidades da população de acordo com os princípios que regem o Sistema Único de Saúde (SUS). Entre as competências instituídas nas Diretrizes Curriculares, necessárias para o exercício da Enfermagem, enfatiza-se: a atenção à saúde, tomada de decisões, comunicação, administração e gerenciamento, educação permanente e liderança ${ }^{(4)}$. Destaca-se que essa última consiste no foco deste estudo.

Liderança consiste em saber conduzir e organizar o trabalho da equipe para o atendimento eficiente. $\mathrm{O}$ líder é entendido como ponto de apoio, seja na educação ou na coordenação do serviço, ele estimula o grupo ao desenvolvimento pleno do seu potencial, o que interferirá diretamente na qualidade da assistência prestada ao indivíduo/comunidade ${ }^{(5)}$.
Destaca-se que a liderança auxilia na construção de um ambiente de trabalho satisfatório, no estabelecimento de vínculos profissionais saudáveis e processos dialógicos entre o enfermeiro e os demais componentes da equipe de enfermagem, assim como potencializa o gerenciamento do cuidado ${ }^{(6)}$. Nesse sentido, a formação de novos perfis de enfermeiros-líderes insere-se com consistência na pauta de discussões dos docentes de Enfermagem, em virtude do contexto atual de saúde precisar, cada vez mais, de profissionais capazes de desempenhar o gerenciamento do cuidado.

Frente ao exposto, emergiu o interesse em estudar a visão dos docentes da Faculdade de Enfermagem da Universidade Federal de Pelotas (UFPel) sobre o processo de ensino-aprendizagem da liderança. Nesta, desenvolve-se, particularmente desde 2009, a construção de uma nova proposta curricular, a fim de formar enfermeiro generalista, crítico, reflexivo, competente técnico-cientificamente, consciente de sua responsabilidade social frente às necessidades de saúde-doença predominantes no país e na região, intervindo de modo efetivo nestas situações e levando em consideração o contexto cultural da sociedade ${ }^{(7)}$.

Assim, este estudo buscou contribuir para a reflexão dos docentes sobre o processo de ensino-aprendizagem da liderança durante a graduação. Ainda, torna-se relevante do ponto de vista social, pois a partir dos resultados obtidos, almeja-se melhorar a qualidade do cuidado prestado aos usuários dos serviços de saúde, a partir do fortalecimento da liderança do enfermeiro. Dessa forma, objetivou-se conhecer a visão dos docentes da Faculdade de Enfermagem da UFPel sobre a formação de enfermeiros-líderes.

\section{MÉTODO}

Este estudo de abordagem qualitativa, do tipo descritivo e exploratório, foi realizado na Faculdade de Enfermagem da UFPel - Rio Grande do Sul. O curso era constituído por 9 semestres, por este motivo participaram da pesquisa 9 docentes, cada um representando um semestre de formação. Optou-se por convidar os docentes responsáveis por cada semestre e os envolvidos na construção e implementação do novo currículo. Desta forma, dentre os 9 docentes, 7 eram regentes de disciplinas e dois participavam de uma comissão que analisa o currículo. Todos possuíam, no mínimo, um ano de experiência como docente na instituição.

Os dados foram coletados, em abril de 2012, por meio de entrevistas semiestruturadas, norteadas por 
um roteiro, o qual tinha como objetivo conhecer a visão dos docentes sobre a formação de enfermeiros-líderes, facilidades e dificuldades durante o processo ensino-aprendizagem da liderança e estratégias utilizadas com o intuito de facilitar a formação do futuro profissional. As entrevistas foram realizadas pelas pesquisadoras no próprio local de estudo, com data e hora acordada previamente com os participantes.

Os participantes foram identificados pela letra ' $\mathrm{D}$ ', seguida de um número ordinal, correspondente à ordem de realização de cada entrevista (D1, D2...D9). As informações coletadas durante a entrevista foram transcritas diariamente visando preservar a veracidade dos dados.

Para o desenvolvimento da pesquisa foram respeitados os princípios éticos estabelecidos pela Resolução n. 196/96 do Conselho Nacional de Saúde que trata da pesquisa envolvendo seres humanos. O estudo foi provado pelo Comitê de Ética em Pesquisa da Faculdade de Enfermagem da UFpel, sob o Parecer n.17/2012.

Os dados foram tratados por intermédio da Análise Temática ${ }^{(8)}$. A partir da análise emergiu dois temas: Visão dos docentes sobre liderança e Estratégias que auxiliam na formação de enfermeiros-líderes.

\section{RESULTADOS}

Ao analisar o perfil dos 9 docentes participantes do estudo, observou-se que a idade variou de 32 anos a 50 anos; em relação à formação, três deles possuem mestrado e seis são doutores; com tempo de experiência profissional entre 8 e 27 anos e o tempo de trabalho na instituição foi de um ano e seis meses a 23 anos. Seis participantes são enfermeiras egressas da mesma instituição em investigação.

\section{Visão dos docentes sobre liderança}

Identificou-se que a liderança é inerente ao trabalho do enfermeiro, cabendo aos docentes facilitar o desenvolvimento desta competência profissional. Desta forma, destaca-se o significado de ser enfermeiro-líder, conforme a visão dos participantes:

O enfermeiro líder para mim é o profissional que sabe ser determinado, pessoa que consegue ver o que é necessário, priorizar, planejar, ter um diagnóstico claro do que está acontecendo e consegue fazer isso funcionar. Acho que consegue botar o processo para ser executado. Uma pessoa líder é aquela que consegue mudanças. (D2)
[...] enfermeiro líder é aquele que consegue ter a equipe de trabalho junto com ele. Trabalhando com objetivo comum, discutindo, fazendo aquela aproximação entre o trabalho e sua equipe com o objetivo comum que é o cuidado de enfermagem. (D3)

Ser líder é quando o profissional tem a capacidade de se unir ao grupo de trabalho e também defender necessidades, seja dos usuários ou dos trabalhadores; e ai conseguir virar uma referência para toda equipe. (D7)

Os docentes também expuseram as principais características que o enfermeiro necessita desenvolver, a fim de atuar enquanto liderança nos serviços de saúde:

Eu acho que a base da liderança é o respeito. A gente consegue ser lider respeitando os outros. E aos pouquinhos podemos ser reconhecidos como líderes dentro de uma equipe. (D4)

[...] enfermeiro líder tem que apresentar responsabilidade, comprometimento, motivação, dinamismo, bom humor, simpatia. Acho que não é só um líder, nem só um enfermeiro. Então acho que tens que ter bom humor e porque isso tudo vai te levar a uma alegria no trabalho. Tenho certeza, as pessoas quando procuram um serviço de saúde, procuram nós da enfermagem. (D9)

Alguns depoimentos refletem a valorização da autonomia dos acadêmicos pelos docentes durante seu processo de ensino-aprendizagem:

[...] nós vamos estimulando no campo prático a autonomia, que eles busquem a identificação e resolução de problemas relacionados à saúde dos usuários. (D1)

[...] percebemos muito no hospital que os alunos vão com a ideia da técnica, da prática em si e, às vezes, não olham para as relações no trabalho, para os problemas da unidade que influenciam naquela assistência. Então, faço com que eles tenham essa autonomia, que eles consigam perceber um pouco e olhar para isso tudo e, assim, dando mais confiança, mostrando um pouco das relações no trabalho, tentando fazer uma relação daquele ambiente, contexto institucional, com a prática, com a influência daquela situação numa prática assistencial. (D6)

Outro aspecto relevante foram as dificuldades encontradas no processo de formação de enfermeiros- 
-líderes, relatadas pelos docentes, as quais estão vinculadas a falta de receptividade e acolhimento dos profissionais aos acadêmicos nos serviços de saúde. Além disso, devido a sua conduta, alguns enfermeiros, não são reconhecidos como exemplos positivos para os acadêmicos, conforme o depoimento a seguir:

A dificuldade é o local onde o aluno está inserido [...] porque os profissionais que estão lá não recebem bem o aluno, o que acaba retraindo. Ele nem consegue ter contato e observar tão bem quanto ele poderia aquele campo, apesar de o professor sempre estar estimulando. E a dificuldade, às vezes, é de eles terem profissionais que, infelizmente, não são o espelho que gostaríamos, mas é o campo de estágio que temos, porém não gostaríamos que eles fossem aquele profissional. Por isso, eu sempre reforço isso, quando vamos para discussão, de você observar e não reproduzir. (D1)

\section{Estratégias que auxiliam na formação de enfermei- ros-líderes}

A inserção do acadêmico no campo prático foi lembrada pelos docentes como uma estratégia, pois, desta forma, tornar-se mais fácil visualizar o exercício da liderança pelo enfermeiro. Fato explicitado no seguinte depoimento:

Utilizamos, quando vamos falar de liderança, nós discutimos dentro do componente [disciplina] apesar de não ser um conteúdo do componente, trabalhamos, mas acho que o mais efetivo, que eles conseguem palpar mais, é quando eles vão ao campo prático, observam, discutem então conseguimos trabalhar. Porque é uma coisa mais visual, é mais fácil para o aluno apesar de trazer na teoria 'ah é assim', quando eles fazem a relação da prática, do que eles observam, é o momento que facilita mais o aprendizado do aluno. (D1)

A importância do entrosamento entre o docente e a equipe igualmente foi referida como estratégia que auxiliam na formação de enfermeiros-líderes:

Eu tento manter um bom relacionamento com a equipe, com todas as pessoas daqui e me coloco sempre como alguém que venha somar, ajudar. E assim, consigo fazer com que os meus alunos se integrem com o pessoal que trabalha aqui e consigo fazer algumas coisas enquanto lider, lider-docente. (D5)

Conforme as declarações, salienta-se a relevância que os docentes destinam ao ensino transversal da liderança, isto é, sua abordagem desde o início do curso e em todos os cenários que permeiam esta formação, considerando sua maturidade e autonomia:

Aqui na faculdade, gestão, agora que é onde nós víamos antes liderança, ela é transversal, ela tem que estar permeando todos os componentes; pelo menos essa é a proposta. Acho que nós temos que pensar na faculdade como um grupo, ter estratégias, é o nosso interesse, isso é uma preocupação. Bom, o que é que nós vamos fazer para começar a discutir a liderança desde o primeiro semestre? (D6)

[...] currículo novo pelo menos, nós temos a competência de gestão/liderança, a competência da gestão perpassa todos os semestres e, claro, depois vai aumentando as habilidades que tem ali dentro, mas uma das coisas é o trabalho em equipe. (D8)

\section{DISCUSSÃO}

A formação de enfermeiros-líderes é um dos principais desafios vivenciados pelos docentes. Desta forma, convém destacar que a liderança na enfermagem representa um fenômeno de influência grupal, tornando indispensável adicionar esforços individuais, a fim de atingir metas traçadas pelo grupo ${ }^{(9)}$. Nesse contexto, entende-se que o bom tempo de atuação dos sujeitos e sua formação são elementos que favorecem sua compreensão e domínio do tema liderança, bem como potencializa o ensino da mesma.

Cabe ao enfermeiro saber liderar, conduzir e planejar o trabalho da equipe, tendo em vista o cuidado eficiente. Pois o ponto de apoio para equipe é o líder, que coordena o serviço, implementa ideias de mudanças e estimula sua equipe para aumentar seu potencial, o que intervirá diretamente na qualidade da assistência. Portanto, a enfermeira torna-se reconhecida pela sua função, enquanto líder influencia seus colaboradores e com seu conhecimento, adquire credibilidade da equipe $^{(5)}$. Esses aspectos emergem nas falas dos docentes, que pontuam uma diversidade de características singulares nos enfermeiros líderes, colocando-os em constante processo de busca na qualificação de seu perfil e forma de atuação.

Ao abordar liderança em Enfermagem, faz-se necessário salientar a relevância da atuação do enfermeiro frente ao cuidado, visto que ele é o foco principal da profissão, fundamentando e justificando as ações da 
equipe de enfermagem. $O$ cuidado está relacionado em promover o bem estar, por isso torna-se necessário que esteja presente nas ações de enfermagem, a fim de que não haja barreira para os processos assistenciais ${ }^{(10)}$. E cabe, igualmente, ao enfermeiro-líder contribuir junto com sua equipe para a prestação de um cuidado de qualidade, utilizando-se da liderança como ferramenta que solidifica gerenciamento e assistência, o que é fortemente reforçado no discurso dos docentes que participaram da pesquisa.

Neste estudo, os docentes destacaram características pessoais para formação do enfermeiro líder, valorizando a responsabilidade, o comprometimento, a motivação e o bom humor. Enfatiza-se que os enfermeiros-líderes buscam aperfeiçoamento contínuo, aliando conhecimento técnico-científico e habilidades pessoais para liderar, correspondendo às expectativas da organização e da equipe, proporcionando uma prática mais crítica, reflexiva e participativa. Estudos destacam as fundamentais características do enfermeiro-líder, sendo elas: motivação, comunicação, agilidade, conhecimento; flexibilidade, confiança, respeito, ética, coerência, saber ouvir, bom humor, tomar decisões, segurança, honestidade, atitude, autoconfiança e autoconhecimento, sendo que várias dessas características foram mencionadas pelos docentes ${ }^{(11-12)}$.

No contexto das instituições de saúde, estas características consistem em estratégias basais, para gerar frutos positivos aos profissionais, sensibilizando-os quanto a sua importância e centralizando o foco do trabalho na prestação do cuidado qualificado ${ }^{(12)}$. Dessa forma, as habilidades pessoais do líder têm grande relevância no processo de liderança, e se torna necessário na influência do processo gerencial do enfermeiro ${ }^{(13)}$. Sendo assim, o líder representa um elo de apoio para equipe, pois tem a responsabilidade de estimular o desenvolvimento coletivo, interferindo diretamente na assistência qualificada ${ }^{(5)}$.

Ainda, enfatizou-se o domínio do conhecimento sobre liderança, o qual permite ao enfermeiro-líder definir a estrutura de trabalho de sua equipe, bem como da instituição, influenciando na administração, na educação, na pesquisa, no processo decisório, no aprimoramento e autonomia, disponibilizando uma assistência eficiente ${ }^{(5)}$.

A abordagem da liderança durante a graduação é essencial para a formação de enfermeiros-líderes capazes de desenvolver atributos que permitam ao profissional exercer em suas atividades, e diferenciar-se no campo de trabalho. Durante o processo de ensino- -aprendizagem da liderança foi possível identificar, na fala dos participantes a valorização e fomentação da autonomia do discente.

Desta forma, a autonomia do profissional enfermeiro, no processo de cuidar no contexto hospitalar torna-se a cada dia mais importante, uma vez que a enfermagem proporciona a possibilidade de rever-se enquanto profissão, assim como se articulando com outras áreas multidisciplinares, em um exercício de interdisciplinaridade. $\mathrm{O}$ processo de autonomia pressupõe que o profissional enfermeiro e a equipe de enfermagem possam intervir no processo de prioridades na assistência. A autonomia está embasada na direção da vontade do indivíduo para a ação, a partir de influências sociais e culturais ${ }^{(14)}$.

Identificou-se que nem todos os profissionais do campo de estágio do estudante exercem o seu papel dentro da equipe da forma que deveriam desempenhar. Sendo assim, é relevante afirmar a importância do enfermeiro-líder. Esse profissional exerce a coordenação da equipe de enfermagem e a gerência de unidades e instituições hospitalares, além disso, é visualizado como referência para os demais trabalhadores e usuários. Portanto, a atualização contínua emerge como uma ferramenta, a qual possibilita ao enfermeiro ser um agente transformador de saberes; $o$ aprimoramento profissional do líder na enfermagem é um processo de trabalho estruturado de maneira coletiva ${ }^{(15)}$.

$\mathrm{O}$ segundo tema diz respeito às estratégias que auxiliam na formação de enfermeiros-líderes. Vários participantes mencionaram que o ensino de liderança é abordado no decorrer de suas práticas, desde os semestres iniciais, mesmo de modo incipiente. Frente ao exposto, apresentam-se algumas estratégias que podem facilitar o processo de ensino-aprendizagem da liderança durante a graduação.

A articulação entre teoria e prática implica nas estratégias que indicam a necessidade da inserção do aluno na realidade da saúde, e faz com que a formação seja centrada na prática, numa contínua aproximação do ensino com o trabalho. Essa articulação se dá por meio de um processo que possibilite o teorizar a partir da prática nos vários cenários, onde é vivenciado o trabalho da enfermagem ${ }^{(16)}$. Contudo, isso requer a construção de vínculos importantes entre serviços e instituições de ensino, o que se mostra um dos principais desafios para promoção da articulação teoria e prática. Frequentemente a fragilidade desse vínculo impede a construção de ações que favoreçam a formação de jovens profissionais, realmente conscientes e capazes de 
intervir sobre a realidade, especialmente no SUS, assim como permitam que os serviços utilizem das inovações e conhecimentos que a acadêmica oportuniza.

A construção de um processo de ensino-aprendizagem trata-se de uma forma investigativa que viabiliza a troca de experiências e a construção de conhecimentos. Essa é uma estratégia fundamentada no conhecimento teórico e pedagógico do professor, bem como a capacidade de sensibilizar frente aos problemas que acontecem no campo de trabalho, com a sutileza de resolvê-los ${ }^{(16)}$. Assim, a troca de experiência requer espaços e saberes que fomentem a reflexão crítica e transformadora, um dos grandes desafios da Política Nacional de Educação Permanente brasileira.

Torna-se importante o bom relacionamento do acadêmico com a equipe, isso leva a pensar no acolhimento entre as equipes, na criação do vínculo entre profissionais de diferentes categorias durante o aprendizado. Diante disso, também é preciso ressaltar o respeito, pois existem opiniões oriundas de diferentes culturas.

Outra estratégia encontrada foi o ensino transversal da liderança. A educação transversal para a formação inserida em todas as disciplinas de um currículo não exime os educadores de pensarem em metodologias específicas e estratégias de ensino que promovam a reflexão ${ }^{(17)}$.

Sobre o processo de ensino-aprendizagem da liderança é imprescindível para a formação de enfermeiros com esta competência. Assim, considera-se a experiência como um aspecto facilitador para o ensino da liderança que permite enriquecer os momentos de aprendizagem ${ }^{(3)}$.

Além disso, a liderança é abordada na graduação desde os semestres iniciais. Resultados semelhantes foram identificados em outros estudos ${ }^{(18)}$, realizados com enfermeiros do contexto hospitalar. Deste modo, acredita-se que cabe aos docentes sensibilizarem-se para a importância do ensino formal da liderança ao longo do curso de graduação, bem como instigarem os discentes para a relevância da liderança no seu processo de trabalho e para as facilidades que a mesma proporcionará ao enfermeiro-líder durante o gerenciamento da unidade e da equipe ${ }^{(3,18)}$.

Incluindo a liderança de forma transversal nos currículos dos Cursos de Enfermagem instrumentalizará o desenvolvimento pessoal e profissional do acadêmico para os cenários de trabalho, surgindo o desafio de desenvolver no campo prático, o gerenciamento e a liderança frente a uma equipe. Essas organizações precisam investir na formação de lideranças, incentivando e implementando estratégias que beneficiem a construção de competências e habilidades ${ }^{(11)}$.

\section{CONCLUSÃO}

Com o desenvolvimento do estudo tornou-se possível conhecer a visão dos participantes sobre a formação de enfermeiros-líderes. Identificaram-se diversas acepções acerca do significado de enfermeiro-líder. Constatou-se que os docentes avaliam a liderança de forma inerente ao trabalho do enfermeiro, concluindo que cabe aos mesmos facilitar ao estudante o desenvolvimento desta competência profissional.

Do mesmo modo, a autonomia foi elencada pelos docentes da instituição, sendo compreendida, como a principal prática pedagógica que interfere no desempenho da liderança. Assim, quando se oferece autonomia ao aluno torna-se mais fácil o processo de ensino-aprendizagem. Contudo, os participantes sinalizam diversidade de outras características necessárias ao enfermeiro-líder, que o destacam no cenário da assistência e como singular para a qualificação do cuidado. Dentre estas características, emergiram algumas pessoais, tais como: responsabilidade, comprometimento, motivação e bom humor. Essas foram, constantemente, vinculadas à necessidade da formação de enfermeiro-líder para atuar de forma coerente, com competência e habilidade. Dessa forma, o docente precisa associar a liderança com os aspectos de desenvolvimento pessoal para a construção dos futuros profissionais. No entanto, conforme os resultados obtidos verificou-se a falta de comprometimento de alguns profissionais do cenário assistencial para a importância de auxiliar na formação de enfermeiros-líderes, conforme preconizado pela Política Nacional de Educação Permanente.

Os docentes expuseram sua sensibilização frente à relevância da formação de enfermeiros-líderes. Esse resultado oferece contribuições positivas para o processo de ensino-aprendizagem, pois os docentes percebem a liderança como uma competência que pode ser desenvolvida. Devido a isso, torna-se imprescindível que o docente conheça o aluno, a fim de promover um processo de ensino-aprendizagem fundamentado em conhecimentos teóricos, práticos e relacionais, para que o futuro enfermeiro realize o gerenciamento do cuidado de enfermagem.

Um aspecto relevante foi a valorização do ensino transversal da liderança. O currículo novo da Faculdade de Enfermagem abriu espaço para a liderança ser abordada de forma transversal no desenrolar dos semestres em todos os cenários que os acadêmicos estão em atuação, para com isso desenvolver competências e habilidades do enfermeiro-líder. Entretanto, verificou-se que os docentes apresentam-se compro- 
metidos com a descrição da abordagem da liderança mas, compreende-se que falta analisar os resultados da implementação do presente currículo, de forma a acrescentar efetivamente na formação de novos profissionais. Porquanto, o currículo ainda está em desenvolvimento e em constante avaliação, sendo um desafio criar novas pesquisas com o intuito de observar o desenvolvimento dessa atividade tão importante no ensino-aprendizagem do enfermeiro-líder.

\section{REFERÊNCIAS}

1. Balsanelli AP, Cunha ICKO. Liderança no contexto da enfermagem. Rev Esc Enferm USP. [Internet] 2006;40(1) [acesso em 20 jan 2012]. Disponível: http:// www.scielo.br/pdf/reeusp/v40n1/a16v40n1.pdf

2. Ito EE, Peres AM, Takahashi RT, Leite MMJ. O ensino de enfermagem e as diretrizes curriculares nacionais: utopia $x$ realidade. Rev Esc Enferm USP. [Internet] 2006;40(4) [acesso em 24 jan 2012]. Disponível: www. scielo.br/pdf/reeusp/v40n4/v40n4a16.pdf

3. Amestoy SC, Cestari ME, Thofehrn MB, Milbrath VM, Trindade LL, Backes VMS. Processo de formação de enfermeiros líderes. Rev Bras Enferm. [Internet] 2010;63(6) [acesso em 27 abr 2012]. Disponível: http:// www.scielo.br/pdf/reben/v63n6/11.pdf

4. Brasil. Conselho Nacional de Educação. Resolução n. 3, de 07 novembro 2001. Institui Diretrizes Curriculares Nacionais do Curso de Graduação em Enfermagem. Brasília; 2001.

5. Gelbcke FL, Souza LA, Dal Sassoi GK, Nascimento E, Bulb MBC. Liderança em ambientes de cuidados críticos: reflexões e desafios à Enfermagem Brasileira. Rev Bras Enferm. [Internet] 2009;62(1) [acesso em 26 mar 2012]. Disponível: http://www.scielo.br/pdf/reben/ v62n1/21.pdf

6. Amestoy SC, Cestari ME, Milbrath VM, Porto AR. Enfermeiras refletindo sobre seu processo de trabalho. Cogitare enferm. [Internet] 2010;15(1) [acesso em 10 mar 2012]. Disponível: http://ojs.c3sl.ufpr.br/ojs2/index. php/cogitare/article/view/17188/11323

7. Sousa ASS, Jardim VMR, Coimbra VCC, Kantorski LP, Oliveira MLM, Franzmann UT, Pinheiro GEW. O projeto pedagógico do Curso de Enfermagem da UFPel. JONAH. [Internet] 2011;1(1) [acesso em 15 fev 2012]. Disponível: http://www.ufpel.edu. $\mathrm{br} / \mathrm{revistas} /$ index.php/enfermagemesaude/article/ viewPDFInterstitial/55/40
8. Minayo MCS. O desafio do conhecimento: Pesquisa qualitativa em Saúde. 12a ed. São Paulo: Hucitec; 2010.

9. Santos I, Castro CB. Estilos e dimensões da liderança: iniciativa e investigação no cotidiano do trabalho de enfermagem hospitalar. Texto Contexto Enferm. [Internet] 2008;17(4) [acesso em 05 abr 2012]. Disponível: http://www.scielo.br/pdf/tce/v17n4/15.pdf

10. Waldow VLR. Estratégias de ensino na enfermagem: enfoque no cuidado e no pensamento crítico. Petropólis: Vozes; 2005.

11. Strapasson MR, Medeiros CRG. Liderança transformacional na enfermagem. Rev Bras Enferm. [Internet] 2009;62(2) [acesso em 16 mar 2012]. Disponível: www.scielo.br/pdf/reben/v62n2/a09v62n2.pdf

12. Amestoy SC, Cestari ME, Thofehrn MB, Milbrath VM. Características que interferem na construção do enfermeiro-líder. Acta Paul. Enferm. [Internet] 2009;22(5) [acesso em 16 mar 2012]. Disponível: www. scielo.br/pdf/ape/v22n5/12.pdf

13. Ribeiro M, Santos SL, Meira TGBM. Reflexão sobre liderança em enfermagem. Esc. Anna Nery. [Internet] 2006;10(1) [acesso em 10 jun 2012]. Disponível: http:// www.scielo.br/pdf/ean/v10n1/v10n1a14.pdf

14. Bueno FMG, Queiroz MS. O enfermeiro e a construção da autonomia profissional no processo de cuidar. Rev Bras Enferm. [Internet] 2006;59(2) [acesso em 12 de mar 2012]. Disponível: http://www.scielo.br/pdf/reben/ v59n2/a19.pdf

15. Maxwell JC. O livro de ouro da liderança. Rio de Janeiro: Thomas Nelson Brasil; 2008.

16. Fernandes JD, Xavier IM, Ceribelli MIPF, Bianco MHC, Maeda D, Rodrigues MVC. Diretrizes curriculares e estratégias para implantação de uma nova proposta pedagógica. Rev Esc Enferm USP. [Internet] 2005;39(4): [acesso em 20 fev 2012]. Disponível: http://www.scielo. br/pdf/reeusp/v39n4/10.pdf

17. Ferreira HM, Ramos LH. Diretrizes curriculares para o ensino da ética na graduação em enfermagem. Acta Paul. Enferm. [Internet] 2006;19(3) [acesso em 02 jun 2012]. Disponível: http://www.scielo.br/pdf/ape/v19n3/ a12v19n3.pdf

18. Amestoy SC. Liderança dialógica: perspectivas na formação de enfermeiros-líderes [tese]. Florianópolis (SC): Universidade Federal de Santa Catarina; 2012. 